\title{
A prospective interventional study evaluating seizure activity during a radiotherapy course for high-grade gliomas (SURF-ROGG)
}

Dirk Rades ${ }^{1 *}$, Jaspar Witteler ${ }^{1}$, Denise Olbrich ${ }^{2}$, Peter Trillenberg ${ }^{3}$, Steven E. Schild ${ }^{4}$, Soeren Tvilsted ${ }^{5}$ and Troels W. Kjaer ${ }^{6}$

\begin{abstract}
Background: Gliomas are often associated with symptoms including seizures. Most patients with high-grade gliomas are treated with radiotherapy or radio-chemotherapy. Since irradiation causes inflammation, it may initially aggravate symptoms. Studies focusing on seizure activity during radiotherapy for gliomas are not available. Such knowledge may improve patient monitoring and anti-epileptic treatment. This study evaluates seizure activity during radiotherapy for high-grade gliomas.

Methods: The primary objective this prospective interventional study is the evaluation of seizure activity during a course of radiotherapy for high-grade gliomas. Progression of seizure activity is defined as increased frequency of seizures by $>50 \%$, increased severity of seizures, or initiation/increase by $\geq 25 \%$ of anti-epileptic medication. Seizure frequency up to 6 weeks following radiotherapy and electroencephalography activity typical for epilepsy will also be evaluated. Patients keep a seizure diary during and up to 6 weeks following radiotherapy. Every day, they will document number (and type) of seizures and anti-epileptic medication. Once a week, the findings of the diary are checked and discussed with a neurologist to initiate or adjust anti-epileptic medication, if necessary. Patients complete a questionnaire regarding their satisfaction with the seizure diary. If the dissatisfaction rate is $>40 \%$, the seizure diary will be considered not suitable for the investigated indication. Thirty-five patients (32 patients plus drop-outs) should be enrolled. With this sample size, a one-sample binomial test with a one-sided significance level of $2.5 \%$ has a power of $80 \%$ to yield statistical significance, if the rate of patients with progression of seizure activity is 30\% (rate under the alternative hypothesis), assuming a 'natural' background progression-rate of 10\% without radiotherapy (null hypothesis).
\end{abstract}

Discussion: If an increase in seizure activity during a course of radiotherapy for high-grade glioma occurs, the findings of this study may pave the way for a larger prospective trial and will likely lead to closer patient monitoring and better anti-epileptic treatment.

Trial registration: clinicaltrials.gov (NCT04552756); registered on 16th of September, 2020.

Keywords: High-grade glioma, Seizures, Radiotherapy, Radio-chemotherapy, Seizure diary

\footnotetext{
*Correspondence: rades.dirk@gmx.net

'Department of Radiation Oncology, University of Lübeck, Ratzeburger Allee 160, 23562 Lübeck, Germany

Full list of author information is available at the end of the article
}

\section{$\triangle B M C$}

(c) The Author(s). 2021 Open Access This article is licensed under a Creative Commons Attribution 4.0 International License, which permits use, sharing, adaptation, distribution and reproduction in any medium or format, as long as you give appropriate credit to the original author(s) and the source, provide a link to the Creative Commons licence, and indicate if changes were made. The images or other third party material in this article are included in the article's Creative Commons licence, unless indicated otherwise in a credit line to the material. If material is not included in the article's Creative Commons licence and your intended use is not permitted by statutory regulation or exceeds the permitted use, you will need to obtain permission directly from the copyright holder. To view a copy of this licence, visit http://creativecommons.org/licenses/by/4.0/ The Creative Commons Public Domain Dedication waiver (http://creativecommons.org/publicdomain/zero/1.0/) applies to the data made available in this article, unless otherwise stated in a credit line to the data. 


\section{Background}

Gliomas represent the most common type of primary brain tumors and are frequently associated with clinical symptoms including seizures [1-7]. The majority of patients with high-grade gliomas (grade III or IV according to the classification of the World Health Organization) receive radiotherapy with or without chemotherapy, either as adjuvant treatment after neurosurgical resection or as definitive treatment after biopsy. Due to an acute inflammatory reaction associated with edema in the irradiated area of the brain and subsequent increase of intracranial pressure, radiotherapy may lead to onset or progression of clinical symptoms including seizures during the course of treatment $[8,9]$. To our knowledge, no studies are available that focused on the subacute effect of radiotherapy on seizure activity during a course of radiation treatment in glioma patients. These data would be important to improve monitoring and anti-epileptic treatment of these patients. This study evaluates the seizure activity during radiotherapy for high-grade (grade III or IV) gliomas.

\section{Methods and design}

This single-arm prospective interventional study performed at a single academic center will evaluate the seizure activity during radiotherapy of high-grade gliomas. The study has been approved by the local ethics committee (University of Lübeck, no. 20-311) and registered at clinicaltrials.gov (identifier: NCT04552756).

\section{Objectives and endpoints}

Primary objective is the evaluation of seizure activity during a course of radiotherapy for high-grade gliomas. Progression of seizure activity during the course of radiotherapy compared to baseline is defined as increase of frequency of seizures by more than $50 \%$, increase of severity of seizures (i.e. increase of generalized seizures by more than 50\%), or increase of the dose of antiepileptic medication by at least $25 \%$ or initiation of antiepileptic medication. The latter criterion was defined in accordance with another situation in radiation oncology, radiotherapy of painful bone metastases [10]. These parameters will be assessed using a seizure diary kept by the patients during the course of radiotherapy. In addition, seizure frequency up to 6 weeks following radiotherapy (seizure diary), patient satisfaction with the seizure diary, and electroencephalography (EEG) activity typical for epilepsy will be evaluated.

\section{Eligibility criteria}

Inclusion criteria include histologically proven newly diagnosed or recurrent grade III or IV glioma (associated or not associated with seizures), indication for normofractionated radiotherapy, Eastern Cooperative Oncology
Group performance score $0-2$, age $\geq 18$ years, written informed consent (taken by physicians registered as investigators for this trial), and capacity of the patient to cooperate (including the use of a seizure diary). Exclusion criteria include pregnancy/lactation and limited legal capacity or being under legal supervision.

\section{Assessments}

Parameters assessed prior radiotherapy include demographics (age, date of birth, gender), medical history, concomitant diseases, concomitant medication including anti-epileptic treatment, physical examination, histology and grade of glioma, upfront surgery, and planned radiotherapy/radio-chemotherapy.

The following parameters will be assessed during the trial (Fig. 1):

\section{Seizure frequency}

The patients keep a seizure diary during radiotherapy and up to 6 weeks following radiotherapy. Every day, the patients document the number and type of seizures and intake of anti-epileptic medication. At the end of radiotherapy, the patients are asked to complete a questionnaire regarding their satisfaction with the seizure diary.

\section{Objective assessment of seizure activity}

To obtain an objective assessment of seizure activity in addition to patient reported outcomes, an EEG is performed during the first and sixth week of radiotherapy, and during the sixth week following radiotherapy.

\section{Adverse Events}

Adverse events other than seizures will be assessed on an ongoing basis according to CTCAE v5.0 [11].

In addition, potential prognostic factors regarding the increase of seizure activity during the course of radiotherapy will be evaluated including seizure activity at baseline, age, gender, glioma grade, recurrent glioma, isocitrate dehydrogenase (IDH1/2) mutation status, methylation of the $\mathrm{O}^{6}$-methylguanine-DNA methyltransferase (MGMT) gene promoter, tumor site, tumor size, cortical involvement and extent of upfront surgery.

\section{Interventions}

Patients receive the same standard treatment for highgrade glioma as they would have received without participation in this study. If necessary, any care and interventions are permitted during the trial for treatmentrelated events and other types of comorbidity. 


\begin{tabular}{|c|c|c|c|c|c|c|}
\hline \multirow[b]{3}{*}{ TIMEPOINT } & \multicolumn{6}{|c|}{ STUDY PERIOD } \\
\hline & \multirow{2}{*}{$\begin{array}{l}\text { Enrolment } \\
\begin{array}{c}\text { Month -1 } \\
\text { to Month } 0\end{array}\end{array}$} & \multirow{2}{*}{$\begin{array}{l}\begin{array}{c}\text { Allocation } \\
\text { Baseline }\end{array} \\
\begin{array}{c}\text { Month -1 } \\
\text { to Month O }\end{array}\end{array}$} & \multicolumn{3}{|c|}{ Post-Allocation } & \multirow{2}{*}{$\begin{array}{c}\text { Close-out } \\
6 \text { weeks after } R T^{*}\end{array}$} \\
\hline & & & $\begin{array}{c}\text { Weekly during } R T \text { (weeks } \\
1-6-6.5, \text { depending on } \\
\text { duration of } R T^{*} \text { ) }\end{array}$ & End of $R T^{\star}$ & $\begin{array}{l}\text { Weekly during weeks } \\
7-12 \text { (weeks 1-6 } \\
\text { following } R T^{*} \text { ) }\end{array}$ & \\
\hline \multirow{4}{*}{$\begin{array}{l}\text { ENROLMENT: } \\
\text { Eligibility screen } \\
\text { Informed consent } \\
\text { Allocation }\end{array}$} & & & & & & \\
\hline & $\mathrm{x}$ & & & & & \\
\hline & $\mathbf{x}$ & & & & & \\
\hline & & $\mathbf{x}$ & & & & \\
\hline \\
\hline \multirow{3}{*}{$\begin{array}{l}\text { Radiotherapy }^{a} \\
\text { Seizure diary } \\
\text { Electroecephalpography (EEG) }\end{array}$} & & & & & & \\
\hline & & $\mathrm{x}$ & $\mathrm{x}$ & $\mathrm{x}$ & $\mathbf{x}$ & $\mathrm{x}$ \\
\hline & & & $x^{a}$ & & $x^{b}$ & \\
\hline \multicolumn{7}{|l|}{ ASSESSMENTS: } \\
\hline \multicolumn{7}{|l|}{$\begin{array}{l}\text { Demographics, medical } \\
\text { history, concomitant } \\
\text { diseases and medication, } \\
\text { physical examination, } \\
\text { histology, grade of glioma, } \\
\text { upfront surgery, planned } \\
\text { radiotherapy and } \\
\text { chemotherapy }\end{array}$} \\
\hline $\begin{array}{l}\text { Patient-reported seizure } \\
\text { activity (seizure diary) }\end{array}$ & & $\mathrm{x}$ & $\mathrm{x}$ & $\mathrm{x}$ & $\mathbf{x}$ & $\mathbf{x}$ \\
\hline $\begin{array}{l}\text { Objective assessment of } \\
\text { seizure activity (EEG) }\end{array}$ & & & $\mathbf{X}^{\mathbf{a}}$ & & $\mathbf{X}^{\mathrm{b}}$ & \\
\hline Adverse events & & & $\mathbf{x}$ & $\mathrm{x}$ & $\mathrm{x}$ & $\mathbf{x}$ \\
\hline Treatment given as & & & $\mathbf{x}$ & $\mathrm{x}$ & $\mathrm{x}$ & $\mathrm{x}$ \\
\hline $\begin{array}{l}\text { Satisfaction with seizure } \\
\text { diary }\end{array}$ & & & & $\mathbf{x}$ & & \\
\hline
\end{tabular}

\section{Glioblastoma (grade IV)}

The treatment of glioblastomas includes resection or biopsy of the tumor followed by radiotherapy of the tumor region plus margins. Radiotherapy is performed with a high-precision technique, i.e. volumetric modulated arc therapy (VMAT). Glioblastoma patients with a Karnofsky performance score $\geq 70$ and younger than 70 years generally receive normo-fractionated radiotherapy [12]. This applies also to patients aged $\geq 70$ years with methylation of the MGMT gene promoter [12]. The dose-fractionation regimen depends on the proximity of the tumor to structures and organs at risk and is either $30 \times 2.0$ Gy over 6 weeks or $33 \times 1.8$ Gy over 6.5 weeks. Tolerance doses of the structures and organs at risk will be considered using the Quantitative Analyses of Normal Tissue Effects in the Clinic (QUANTEC) [13].

Radiotherapy should be combined with temozolomide (TMZ), whenever reasonable. TMZ is given concurrently with radiotherapy plus sequentially following radiotherapy. The dose of concurrent TMZ is $75 \mathrm{mg} /$ $\mathrm{m} 2 /$ day, administered on 7 days per week during the entire course of radiotherapy. Concurrent treatment is followed by 6 courses of sequential TMZ (150-200 mg/ $\mathrm{m} 2$ /day on 5 consecutive days every 4 weeks).

\section{Anaplastic astrocytoma and anaplastic oligodendroglioma (grade III)}

The treatment of grade III gliomas also includes resection or biopsy of the tumor. Postoperative treatment varies between anaplastic astrocytomas and anaplastic oligodendrogliomas. Most patients receive postoperative radiotherapy. Anaplastic astrocytomas with IDH1/2 wild type are generally treated like glioblastomas. If anaplastic astrocytomas show an IDH1/2 mutation, postoperative treatment starts with radiotherapy alone followed by sequential chemotherapy with TMZ (150-200 mg/m2/day on 5 consecutive days every 4 weeks) or 4 courses of PCV including procarbazine $(60 \mathrm{mg} / \mathrm{m} 2$ on days $8-21)$, 
lomustine $(110 \mathrm{mg} / \mathrm{m} 2 /$ day on day 1$)$ and vincristine $(1.4 \mathrm{mg} / \mathrm{m} 2 /$ day, maximum absolute dose $=2.0 \mathrm{mg}$, on days 8 and 29, every (6-)8 weeks) [12]. To reduce toxicity, vincristine may be omitted. In case of an IDH1 mutation, astrocytomas and oligodendrogliomas can be differentiated by the $1 \mathrm{p} / 19 \mathrm{q}$ co-deletion. Astrocytomas do not have a $1 \mathrm{p} / 19 \mathrm{q}$ co-deletion, whereas the codeletion is present in oligodendrogliomas. Postoperative treatment of anaplastic oligodendrogliomas with IDH mutation and $1 \mathrm{p} / 19 \mathrm{q}$ co-deletion starts with radiotherapy alone followed by chemotherapy with 4 courses of PCV [12]. Again, vincristine may be omitted to reduce treatment-related toxicity.

\section{Seizure diary}

The patients keep a seizure diary during the period of radiotherapy and up to 6 weeks following radiotherapy. Every day, the patients document the number and type of seizures and intake of anti-epileptic medication.

Once a week during the radiotherapy course, the seizure diary will be reviewed by a medical staff member. During the 6 weeks following radiotherapy, the patients are contacted by phone (to minimize the number of visits to the hospital) once a week to obtain the information from the seizure diary. During and following radiotherapy, the weekly findings of the seizure diary are discussed with a neurologist to initiate or adjust antiepileptic medication, if necessary. At the end of radiotherapy, the patients are asked to complete a questionnaire regarding their satisfaction with the seizure diary. In case of a dissatisfaction rate $>40 \%$, the seizure diary will be considered not suitable for patients with highgrade gliomas.

\section{Electroencephalography (EEG)}

The patients receive an EEG during the first and the sixth week of radiotherapy, as well as during the sixth week following radiotherapy. Activity typical for epilepsy includes spike waves, sharp waves and/or sharp slow waves and is classified as absent or present.

\section{Sample size calculations}

The main goal of the study is to generate objective data on the occurrence, frequency and severity of seizures and the use of anti-epileptic medication during the course of radiotherapy applying standardized questionnaires, in order to evaluate the potential effect of radiotherapy in patients with high-grade gliomas and generate hypotheses. Thirty-two patients are required for the statistical analyses. Assuming that $10 \%$ of patients do not fulfil these requirements, a total of 35 patients should be enrolled to this trial. With this sample size, a one-sample binomial test with a one-sided significance level of $2.5 \%$ has a power of $80 \%$ to yield statistical significance if the rate of patients with progression of seizure events during the course of radiotherapy is $30 \%$ (rate under the alternative hypothesis), assuming a 'natural' background progression-rate of $10 \%$ without radiotherapy (null hypothesis). The latter rate was chosen after discussions with experienced neurologists. If the natural course of the disease would lead to a progression-rate of 5\% without radiotherapy, the power increases to $98 \%$. Recruitment should be completed within 12 months. The radiotherapy period is 6-6.5 weeks, and follow up is 6 weeks. Thus, duration of the trial is about 15 months.

\section{Statistical methods for investigated endpoints}

The focus of the statistical analysis is descriptive and exploratory in nature. If statistical tests are applied, they are to be interpreted on an exploratory perspective. All data recorded in the case report forms describing the study population (demographic and clinical characteristics, at baseline) will be analyzed descriptively. Categorical data will be presented in tables with frequencies and percentages. Continuous data will be summarized with at least the following: Frequency (n), median, quartiles, mean, standard deviation (standard error), minimum and maximum. Number of patients with protocol deviations during the study and listings describing the deviations will be provided. The seizure frequency at baseline and during the course of radiotherapy will be calculated by summing the number of seizures in each period and dividing by the total duration (days), excluding days with no available diary data, and multiplying by 7 to normalize to a weekly rate. The resulting normalized frequencies form the basis for calculating the composite primary endpoint. The point estimate of the rate of progressors and the associated 95\% confidence interval will be presented. To test whether the rate of progressions is significantly increased beyond 10\%, the one-sided binomial test at a one-sided $2.5 \%$ significance level will be applied.

Furthermore, a logistic regression model including baseline seizure including seizure activity at baseline, age ( $\leq 59$ vs. $\geq 60$ years), gender, glioma grade (grade III vs. IV), recurrent glioma (no vs. yes), IDH1/2 mutation status (mutation vs. wild type), methylation of the MGMT gene promoter (yes vs. no), tumor site (frontal vs. temporal vs. parietal vs. other sites), tumor size ( $\leq$ median vs. > median), cortical involvement (yes vs. no) and extent of surgery (no resection/biopsy only vs. subtotal resection vs. gross total resection) will be fitted to identify potentially relevant prognostic factors [14].

Adjusted odds ratios and $95 \%$ confidence interval (Wald $\chi^{2}$ ) will be derived. In addition, each component of the primary composite endpoint will be subjected to a separate statistical analysis using the same methods 
described above. For exploratory purposes, the analyses described above will also be conducted by focusing on the seizures classified as generalized and generalized/ grand mal only.

In order to describe the time profiles of seizure frequencies in more detail, normalized seizure frequencies over time will be calculated within 3-week intervals, namely weeks $1-3$ and 4-6 during radiotherapy, and weeks 1-3 (7-9 in total) and 4-6 (10-12 in total) following radiotherapy. These frequencies will be subjected to descriptive statistics as well as graphical presentations by means of box-and whisker diagrams. For exploratory purposes, the Wilcoxon signed-rank test will be applied to compare the two-time windows during the course of radiotherapy; the Friedman-Test will be applied to assess whether there is any difference in seizure frequencies between all of the time intervals during the course of radiotherapy and thereafter.

In addition, the percent change from baseline in seizure frequency will be considered and subjected to descriptive analysis. For further exploratory analysis, the rates of patients experiencing any seizure (yes/no) at baseline and at each time interval will be estimated together with their associated confidence intervals. Subsequent analyses focus on the clinically relevant generalized seizures only.

Patient satisfaction with the seizure diary will be assessed at the end of radiotherapy using a questionnaire and subjected to descriptive analysis. In case of a dissatisfaction rate $>40 \%$, the seizure diary will be considered not suitable for patients with high-grade gliomas. EEG activity typical for epilepsy will be performed during the first and sixth week of radiotherapy, and the sixth week following radiotherapy. EEG activity typical for epilepsy is classified as absent or present. Statistical analysis is focused on data description only. A mean change to baseline (during first week of radiotherapy) by $50 \%$ regarding the number of patients with EEG activity typical for epilepsy will be considered clinically relevant.

\section{Data management and monitoring}

Patients can be identified only by the individual patient number, date of birth and gender. A patient list will be kept at the trial center alone. The data will be pseudonymized prior to analyses and handled in accordance with the General Data Protection Regulation. Originals of the key trial documents will be stored at the contributing center (sponsor's site) for at least 10 years following the final report. The principal investigator will store administrative documents, the patient list, signed informed consent forms, copies of documentation forms and general documentation. Original patient files must be kept for 30 years according to the German regulations for radioprotection. Initiation of the study and on-site monitoring will be performed by the ZKS Lübeck. Regular audits are not planned but may be performed if considered necessary. Since this trial is not related to the German pharmaceutical or medicinal product act, inspections of higher federal authorities are not scheduled. A data monitoring committee is not necessary, because the patients do receive the same treatment for highgrade glioma as outside this trial. The coordinating investigator will work towards comprehensive dissemination of the study findings. Coordinating investigator, biostatistician and staff members involved in the trial will provide a study report. Study results will be published in a peer-reviewed journal and are planned to be presented at scientific meetings. Publications will be coordinated with and supported by a professional biostatistician. For publications the acronym SURF-ROGG will be used. Data analysts and statisticians are blinded.

\section{Discussion}

Primary brain tumors such as gliomas can be associated with seizures. For patients with grade III or IV gliomas, pre-treatment seizure rates of $29-67 \%$ and $9-45 \%$, respectively, were reported [3, 15-19]. Moreover, in a study from our group, the prevalence of seizures prior to radiotherapy was $48.8 \%$ in patients with grade III gliomas and $21.5 \%$ in patients with grade IV gliomas, respectively [14].

Radiotherapy improves long-term seizure outcomes in glioma patients. In a retrospective study of 43 patients with diffuse gliomas (33 patients with a grade II glioma and 10 patients with a grade III glioma), seizure reduction of $\geq 50 \%$ compared to baseline was observed in 31 patients (72\%) at 3 months following radiotherapy [20]. Moreover, in a randomized trial comparing early radiotherapy with 54 Gy in 30 fractions to radiotherapy performed only at the time of progression, seizure control at 1 year was better in the early radiotherapy group [21]. However, during the course of radiotherapy, seizures may occur for the first time or the frequency of seizures may increase, because radiotherapy leads to an acute inflammatory reaction, which can be associated with edema and increased intracranial pressure $[8,9]$. In 2004, Bhansali et al. reported 11 patients with radiationinduced brain disorders [8]. Four of these patients (36\%) had developed generalized seizures. In a review article published in 2007, seizures were reported to be symptoms of both acute radiation encephalopathy and late radiation-related necrosis [9]. However, no study has been available so far that evaluated the effect of irradiation to the brain on seizure activity during the course of radiotherapy for high-grade gliomas. However, these data would be very important in order to improve the monitoring and, if required, the anti-epileptic treatment of these patients. Therefore, the SURF-ROGG trial has 
been designed that will evaluate the seizure frequency during a course of radiotherapy for high-grade (grade III or IV) gliomas. Patients with low-grade (grade I or II) gliomas will not be included, because the treatment of these tumors and the dose-fractionation of radiotherapy are almost always different from the treatment of highgrade tumors [12].

In this trial, progression of seizure activity is defined as increase of seizure frequency by more than $50 \%$, increase of severity of seizures (i.e. increase of generalized seizures by more than $50 \%$ ), or initiation or increase of anti-epileptic medication by at least $25 \%$. Evaluation of seizure activity is mainly based on patient-reported outcomes, i.e. on a seizure diary kept by the patients during the period of radiotherapy and up to 6 weeks following radiotherapy. Every day, the patients document the number and type of seizures, as well as the intake of antiepileptic medication. At the end of radiotherapy, the patients are asked to complete a questionnaire regarding their satisfaction with the seizure diary. In addition to the patient-reported outcomes, EEG activity typical for epilepsy will be evaluated to receive also objective data.

If the SURF-ROGG trial shows an increase in seizure activity during the course of radiotherapy for high-grade gliomas, the findings of this trial may pave the way for a larger prospective trial and will likely contribute to closer patient monitoring and better anti-epileptic treatment.

\section{Abbreviations \\ CTCAE: Common Terminology Criteria for Adverse Events; EEG: Electroencephalography; GCP: Good Clinical Practice; IDH: Isocitrate Dehydrogenase; MGMT: $\mathrm{O}^{6}$-Methyl-Guanine-DNA Methyl-Transferase; PCV: Procarbazine, Lomustine and Vincristine; QUANTEC: Quantitative Analyses of Normal Tissue Effects in the Clinic; SURF-ROGG: SeizURe Frequency during a Radiotherapy cOurse for high-Grade Gliomas; TMZ: Temozolomide; VMAT: Volumetric Modulated Arc Therapy; ZKS: Zentrum für Klinische Studien (Centre for Clinical Trials)}

\section{Acknowledgements}

Not applicable.

\section{Authors' contributions}

D.R., J.W., D.O., P.T., S.E.S., S.T. and T.W.K. participated in the development of the protocol. D.R. and S.E.S. drafted the manuscript. All authors have read and approved the manuscript.

\section{Funding}

The SURF-ROGG trial is part of the NorDigHealth project and funded by the European Regional Development Fund through the Interreg DeutschlandDanmark program (reference: 087-1.1-18). Sponsor is the University Medical Center Schleswig-Holstein, Germany. Funding body and sponsor will have no role with respect to designing the study, handling the data and writing the article. Open Access funding enabled and organized by Projekt DEAL.

\section{Availability of data and materials}

Not applicable, because no data have been generated until now. The trial was registered at clinicaltrials.gov (NCT04552756).

\section{Declarations}

Ethics approval and consent to participate

The SURF-ROGG trial was approved by the local ethics committee (University of Lübeck, no. 20-311). The trial is performed according to the Declaration of Helsinki and the principles of Good Clinical Practice (GCP). Patients are included only after written informed consent.

\section{Consent for publication}

Not applicable.

\section{Competing interests}

Dirk Rades is associate editor of BMC Cancer. Otherwise, no competing interests exist regarding this trial.

\section{Author details}

'Department of Radiation Oncology, University of Lübeck, Ratzeburger Allee 160, 23562 Lübeck, Germany. ${ }^{2}$ The Centre for Clinical Trials Lübeck, Lübeck, Germany. ${ }^{3}$ Department of Neurology, University of Lübeck, Lübeck, Germany. ${ }^{4}$ Department of Radiation Oncology, Mayo Clinic Scottsdale, Scottsdale, AZ, USA. ${ }^{5}$ Research Projects and Clinical Optimization, Zealand University Hospital, Koege, Denmark. ${ }^{6}$ Neurological Department, Zealand University Hospital, Roskilde, Denmark.

Received: 18 September 2020 Accepted: 29 March 2021

Published online: 09 April 2021

\section{References}

1. Jairam V, Kann BH, Park HS, Miccio JA, Beckta JM, Yu JB, et al. Defining an intermediate-risk group for low-grade glioma: a national cancer database analysis. Anticancer Res. 2019;39(6):2911-8. https://doi.org/10.21873/antica nres. 13420 .

2. Samudra N, Zacharias T, Plitt A, Lega B, Pan E. Seizures in glioma patients: an overview of incidence, etiology, and therapies. J Neurol Sci. 2019;404:805. https://doi.org/10.1016/j.jns.2019.07.026.

3. IJzerman-Korevaar M, Snijders TJ, de Graeff A, SCCM T, FYF d V. Prevalence of symptoms in glioma patients throughout the disease trajectory: a systematic review. J Neuro-Oncol. 2018;140(3):485-96. https://doi.org/10.1 007/s11060-018-03015-9.

4. Kerkhof M, Dielemans JC, van Breemen MS, Zwinkels $H$, Walchenbach R, Taphoorn MJ, et al. Effect of valproic acid on seizure control and on survival in patients with glioblastoma multiforme. Neuro-Oncology. 2013;15(7):9617. https://doi.org/10.1093/neuonc/not057.

5. Izumoto S, Miyauchi M, Tasaki T, Okuda T, Nakagawa N, Nakano N, et al. Seizures and tumor progression in glioma patients with uncontrollable epilepsy treated with perampanel. Anticancer Res. 2018;38(7):4361-6. https://doi.org/10.21873/anticanres.12737.

6. Dobran M, Nasi D, Chiriatti S, Gladi M, Somma LD, lacoangeli M, et al. Prognostic factors in glioblastoma: is there a role for epilepsy? Neurol Med Chir (Tokyo). 2018;58:110-5 2018.

7. Palombi L, Marchetti P, Salvati M, Osti MF, Frati L, Frati A. Interventions to reduce neurological symptoms in patients with GBM receiving radiotherapy: from theory to clinical practice. Anticancer Res. 2018;38(4):2423-7. https:// doi.org/10.21873/anticanres.12494.

8. Bhansali A, Banerjee AK, Chanda A, Singh P, Sharma SC, Mathuriya SN, et al. Radiation-induced brain disorders in patients with pituitary tumours. Australas Radiol. 2004;48(3):339-46. https://doi.org/10.1111/j.0004-8461.2003. 01237.x.

9. Singh G, Rees JH, Sander JW. Seizures and epilepsy in oncological practice: causes, course, mechanisms and treatment. J Neurol Neurosurg Psychiatry. 2007;78:342-9.

10. Chow E, Hoskin P, Mitera G, Zeng L, Lutz S, Roos D, et al. International bone metastases consensus working party: update of the international consenus on palliative radiotherapy endpoints for future clinical trials in bone metastases. Int J Radiat Oncol Biol Phys. 2012;82(5):1730-7. https://doi.org/1 0.1016/j.jijobp.2011.02.008.

11. National Institutes of Health/National Cancer Institute. Common Terminology Criteria for Adverse Events (CTCAE) version 5.0: National Institutes of Health/National Cancer Institute; 2017.

12. Weller M, van den Bent M, Tonn JC, Stupp R, Preusser M, Cohen-JonathanMoyal E, et al. European Association for Neuro-Oncology (EANO) Task Force 
on Gliomas: European Association for Neuro-Oncology (EANO) guideline on the diagnosis and treatment of adult astrocytic and oligodendroglial gliomas. Lancet Oncol. 2017;18:e315-29.

13. Bentzen SM, Constine LS, Deasy JO, Eisbruch A, Jackson A, Marks LB, et al. Quantitative analyses of Normal tissue effects in the clinic (QUANTEC): an introduction to the scientific issues. Int J Radiat Oncol Biol Phys. 2010;76(3 Suppl):S3-9. https://doi.org/10.1016/j.jijrobp.2009.09.040.

14. Witteler J, Kjaer TW, Tvilsted S, Schild SE, Rades D. Seizures prior to radiotherapy of gliomas: prevalence, risk factors and survival prognosis. Anticancer Res. 2020;40(7):3961-5. https://doi.org/10.21873/anticanres.14388.

15. Englot DJ, Chang EF, Vecht CJ. Epilepsy and brain tumors. Handb Clin Neurol. 2016;134:267-85. https://doi.org/10.1016/B978-0-12-802997-8.000165 .

16. Fan X, Li Y, Shan X, You G, Wu Z, Li Z, et al. Seizures at presentation are correlated with better survival outcomes in adult diffuse glioma: a systematic review and meta-analysis. Seizure. 2018;59:16-23. https://doi. org/10.1016/j.seizure.2018.04.018.

17. Hwang SL, Lieu AS, Kuo TH, Lin CL, Chang CZ, Huang TY, et al. Preoperative and postoperative seizures in patients with astrocytic tumours: analysis of incidence and influencing factors. J Clin Neurosci. 2001;8(5):426-9. https:// doi.org/10.1054/jocn.2000.0825

18. Hwang $\mathrm{SL}$, Lin $\mathrm{CL}$, Lee KS, Lieu AS, Kuo TH, Chang CZ, et al. Factors influencing seizures in adult patients with supratentorial astrocytic tumors. Acta Neurochir. 2004;146(6):589-94. https://doi.org/10.1007/s00701-004-02 66-8.

19. Toledo M, Sarria-Estrada S, Quintana M, Maldonado X, Martinez-Ricarte F, Rodon J, et al. Epileptic features and survival in glioblastomas presenting with seizures. Epilepsy Res. 2017;130:1-6. https://doi.org/10.1016/j. eplepsyres.2016.12.013.

20. Rudà R, Magliola U, Bertero L, Trevisan E, Bosa C, Mantovani C, et al. Seizure control following radiotherapy in patients with diffuse gliomas: a retrospective study. Neuro-Oncology. 2013;15(12):1739-49. https://doi.org/1 0.1093/neuonc/not109.

21. Van den Bent MJ, Afra D, de Witte O, Ben Hassel M, Schraub S, Hoang-Xuan $K$, et al. EORTC radiotherapy and brain tumor groups and the UK Medical Research Council: long-term efficacy of early versus delayed radiotherapy for low-grade astrocytoma and oligodendroglioma in adults: the EORTC 22845 randomised trial. Lancet. 2005;366(9490):985-90. https://doi.org/10.1 016/50140-6736(05)67070-5.

\section{Publisher's Note}

Springer Nature remains neutral with regard to jurisdictional claims in published maps and institutional affiliations.

Ready to submit your research? Choose BMC and benefit from:

- fast, convenient online submission

- thorough peer review by experienced researchers in your field

- rapid publication on acceptance

- support for research data, including large and complex data types

- gold Open Access which fosters wider collaboration and increased citations

- maximum visibility for your research: over $100 \mathrm{M}$ website views per year

At BMC, research is always in progress.

Learn more biomedcentral.com/submissions 